\title{
FRANCISCO GIRALTE Y EL SEPULCRO DEL OBISPO GUTIERRE DE CARVAJAL
}

\author{
Luis Vasallo Toranzo \\ Universidad de Valladolid \\ Sergio Pérez Martín \\ Fundación Rei Afonso Henriques
}

La alta tasación alcanzada por el sepulcro del obispo Gutierre de Carvajal, obra de Francisco Giralte, motivó un pleito al que fueron llamados los principales artistas de Toledo, Alcalá y Madrid. Sus testimonios, realizados en el crucial momento en que se produjo la muerte de Berruguete y llegó la corte a Madrid, son muy útiles para conocer la estimación artística de una obra, de la que personajes como Pompeyo Leoni, Nicolás de Vergara el Viejo, Jácome Trezo o Juan Bautista de Toledo ponderaron la perfección técnica, la belleza de su talla, la multiplicación de personajes representados junto al finado y la voluntad retratística presente en todos ellos.

Palabras clave: Sepulcro; Escultura; Francisco Giralte; Renacimiento; Manierismo.

FRANCISCO GIRALTE AND THE TOMB OF BISHOP GUTIERRE DE CARVAJAL

The high valuation placed on the tomb of Bishop Gutierre de Carvajal, sculpted by Francisco de Giralte, resulted in a lawsuit for which the most important artists from Toledo, Alcalá and Madrid were called to testify. Their testimonies, made during the crucial moment when Berruguete died and the court arrived at Madrid are very useful for understanding the artistic appreciation of a work. Thus, relevant artists of the period -Pompeyo Leoni, Nicolás Vergara el Viejo, Jácome Trezo or Juan Bautista de Toledo- attested to the perfect technique, the beauty of the carving, the multiplicity of personages represented next to the dead Bishop, and the wish to achieve their portrait likenesses.

Key words: Tomb; Sculpture; Francisco Giralte; Renaissance; Mannerism.

La marcha de Alonso Berruguete a Toledo en 1539 permitió alentar las aspiraciones de otros escultores para ocupar su puesto en la villa del Pisuerga. El primero en alcanzar dicho objetivo fue Juan de Juni, quien desde Salamanca se desplazará hasta Valladolid en 1542 para encargarse del retablo del Santo Entierro para fray Antonio de Guevara ${ }^{1}$. Por esas fechas regresaba Francisco Giralte a Palencia después de haber participado a las órdenes de Berruguete en la sillería toledana; a partir

\footnotetext{
${ }^{1}$ Fernández del Hoyo, 2012: 56.
} 
de entonces iniciará un acercamiento hacia la localidad pinciana, encaminado a lograr su asentamiento definitivo, como demuestra la disputa con Juni por el contrato del retablo de La Antigua. El propio maestro de Paredes, consciente de estos movimientos, pretenderá resguardar sus intereses en la villa utilizando a su sobrino Inocencio, a quien favorecerá para fundar un taller vallisoletano al finalizar la década de $1540^{2}$. Todas estas maniobras se resolverán en 1548-9 cuando el obispo Gutierre de Carvajal llame a Giralte para encargarle las obras de escultura de su capilla madrileña ${ }^{3}$.

No están claras las razones de dicha comisión. Aunque el obispo tenía casa en Valladolid, el bagaje profesional de Giralte en la localidad era muy pobre, apenas el pequeño retablo para el doctor Luis del Corral en la iglesia de La Magdalena y alguna que otra obra de devoción para cofradías penitenciales $^{4}$. A este respecto, Alonso Berruguete parece haber jugado un papel relevante, pues no resulta verosímil la elección autónoma del clérigo ${ }^{5}$. No es posible afirmar, de acuerdo con la información actual, que Gutierre de Carvajal intentase contratar primero a Berruguete ${ }^{6}$, pues, aun cuando la muerte del cardenal Tavera en 1545 hubiera allanado el camino, Berruguete estaba terminando los remates de la silla arzobispal del coro toledano y pronto iba a comenzar su relación con la fundación hospitalaria del difunto cardenal. Sin embargo, sí puede aventurarse su intervención en la elección de Giralte, seguramente impulsando unas negociaciones que debieron de comenzar en $1547-8^{8}$ y que permitieron alejar a un peligroso competidor para el reactivado taller berruguetesco de Valladolid".

Dichas conversaciones parecen haberse centrado en el tipo de relación contractual que debía ligar a Giralte y a Carvajal. El obispo se había concertado en 1535 con el entallador e imaginario Francisco Hernández para que se ocupase del retablo y su sepulcro, así como de todo aquello que se le ordenase, sin poder aceptar otras obras, a cambio de 40.000 maravedís anuales ${ }^{10}$. Este tipo de contrato distaba mucho de los llamados a tasación que comenzaban a extenderse desde el se-

\footnotetext{
${ }^{2}$ VASAllo Toranzo, 2012: 29

${ }^{3}$ La llegada del escultor a Madrid la fecha él mismo en 1549 en el pleito que lo enfrentó a los herederos de don Gutierre por el cobro de su sepulcro. En marzo de 1562 planteó la siguiente pregunta a sus testigos: si saben que el obispo lo sacó de su propia cassa e naturaleza, que hera en la çibdad de Palençia, haziéndole yr con toda su cassa como fue para entender en la dicha obra e otras obras que por él se hizieron en la dicha capilla de la dicha villa de Madrid, a donde se ocupó en hazerla por su parte con diez y ocho offiçiales continos, personas primas en el arte, estando todos a costa del dicho Francisco Giralte, por tienpo y espaçio de treze años... Archivo de la Real Chancillería de Valladolid (ARChVa), Pl. Civiles, Lapuerta (F), C. 358-1, 14 pieza.

${ }^{4}$ Urrea, 1996: 149, Parrado del Olmo, 2009: 194-226.

5 VASAllo TORAnZO, 2012: 29.

${ }^{6}$ Tampoco la relación proyectiva de Alonso Berruguete con el amueblamiento de la Capilla del Obispo, aunque sí son evidentes los vínculos profesionales y económicos del escultor con varios miembros de la familia del prelado. Arias Martínez, 2011: 48 y 51.

${ }^{7}$ Que Berruguete estaba al tanto de las negociaciones lo aclara el arquitecto Hernán González, quien en 1549,...estando este testigo en la çibdad de Toledo, oyó dezir públicamente..., espeçialmente se acuerda que hera el uno dellos Berruguete y el otro Niculas de Vergara y otros que no se acuerda, que el dicho Francisco Giralte se venía de asiento a esta villa a entender en las obras del dicho obispo de Plasencia que hazía para su capilla. ARChVa, Pl. Civiles, Lapuerta (F), C. 358-1, 14 pieza.

${ }^{8}$ Como dice el platero Sebastián Álvarez, ... antes quel dicho Francisco Giralte viniesse a esta villa a entender en las dichas obras, puede aver más de los dichos treze años que dize la pregunta, estando este testigo en la villa de Valladolid, habló e vido al dicho Francisco Giralte, el qual dixo e çertificó a este testigo cómo por mandado del dicho obispo venía a esta villa de Madrid a entender en las dichas obras quel dicho obispo quería hazer para la dicha su capilla. ARChVa, Pl. Civiles, Lapuerta (F), C. 358-1, 14 a pieza.

9 Sorprende el cambio radical de opinión del tribunal de la Chancillería en el pleito entre los parroquianos de La Antigua y Juan de Juni, que pasó de dictar una sentencia favorable a Giralte en 1547, a otra totalmente contraria en 1549; sentencia, además, que no fue apelada por los parroquianos ni por el artista perjudicado y sí por Juni, que veía muy mermados sus ingresos. En relación a esto hay que recordar que un hermano del obispo, el licenciado Juan de Vargas, fue primero alcalde de la audiencia vallisoletana y después oidor en ella y que Berruguete era escribano de la misma.

${ }^{10}$ Martín Ortega, 1957: 68-70.
} 
gundo cuarto del XVI, con los que los comitentes pretendían asegurarse la calidad de la obra y los artistas recibir un precio justo ${ }^{11}$. De hecho, Alonso Berruguete había acordado de esta manera el remate de la silla arzobispal de Toledo, valorada por los tasadores en más del doble del precio estimado en el convenio inicial ${ }^{12}$. No conocemos el tipo de acuerdo al que llegaron el obispo y Giralte en 1548, ni si fue escrito o de palabra, lo único cierto es que extrañamente no se presentó documento notarial alguno en el pleito que enfrentó al escultor con el hijo del obispo a causa de la tasación del sepulcro. Sí sabemos que, a excepción de los emolumentos del escultor, ahora estimados por tasadores, se pactó, como en 1535, la puesta a disposición del artista y su familia de una vivienda propiedad de don Gutierre, la aportación por parte del obispo de los materiales y quizás también la exclusividad del trabajo del maestro en favor del benefactor, aunque se conoce al menos un retablo realizado por Giralte para otro comitente antes de $1553^{13}$.

La llegada del palentino a Madrid se produjo, como se ha indicado más arriba, en 1549. Primero acudió en solitario y al cabo de unos meses llegó el resto de la familia: su mujer, sus hijos y su padre. No es posible conocer lo que se encontró en la capilla. Ésta había sido fundada por el licenciado Francisco de Vargas para alojar los restos del labrador Isidro, si bien, a su muerte, acaecida en 1524, sólo la había sacado de cimientos ${ }^{14}$. Fue su hijo Gutierre quien se ocupó de terminarla, aunque no en 1535, como se ha dicho ${ }^{15}$ atendiendo a que en dicha fecha el mencionado Francisco Hernández se comprometía a entallar el retablo y otro enterramiento -se supone que el existente era el de San Isidro- para el prelado. El inicio de la obra del Alcázar Real, que monopolizó materiales y oficiales ${ }^{16}$, y un pleito que enfrentó al obispo con la parroquia a cuenta de la ubicación del cuerpo del futuro San Isidro ${ }^{17}$, retrasaron la conclusión de la capilla. De hecho, el contrato con Francisco Hernández no debió de llevarse a efecto, o al menos hubo de rescindirse pronto, pues éste siguió contratando con particulares (1538 y 1539) ${ }^{18}$ para poco después (1540) pasar a trabajar en el Alcázar ${ }^{19}$. Además, el litigio del obispo con la iglesia de San Andrés no se sustanció hasta 1544, cuando los parroquianos recuperaron la reliquia, a raíz de lo cual el clérigo decidió convertir la capilla en el panteón de su linaje. Fue entonces cuando resolvió trasladar los cuerpos de sus padres desde la antigua capilla familiar de San Francisco, decisión que contradecía actuaciones muy recientes de engalanamiento de dicho espacio ${ }^{20}$.

Acorde con este relato, Rodrigo Gil de Hontañón declaraba en 1543...

...que ha thenido e tiene cargo de hazer e haze la obra de cantería de la yglesia de Salamanca, e yglesia de Astorga, e de la yglesia de Galiçia, e de la yglesia de Çiudad Rodrigo, e de la yglesia de Segovia, e de la yglesia de Valladolid, e la capilla del obispo de Plazençia en San Andrés de la villa de Madrid de albañería, e otras obras de las que dicho tiene que son de albañería e cantería, e porque a sydo en tasar el quarto rreal de las casas del arçobispo de Toledo que tiene en Alcalá de Henares... ${ }^{21}$.

\footnotetext{
11 MARÍAS, 1989: 462.

12 Arias Martínez, 2011: 162-4.

13 Martín Ortega, 1961: 123 y 126-7.

14 Así se indica en las constituciones de la fundación (FERnÁndez Hoyos, 1994: 161), algo que corroboran los testigos en el pleito que estamos glosando aquí: ARChVa, Pl. Civiles, Lapuerta (F), C. 357-1, $7^{\text {a }}$ pieza, testimonio de Gaspar de Bedoya, secretario que había sido del obispo.

${ }^{15}$ LAMPÉREZ y ROMEA, 1898: 58.

16 Gerard, 1984, 25.

${ }^{17}$ Martí y Monsó, 1989-1901: 380.

18 Martín Ortega, 1957: 68-73, Estella, 1980: 58-60 y Río de la Hoz, 2001: 297-8.

19 Cervera Vera, 1994: 50 y ss.

${ }^{20}$ Martín Ortega, 1957: 66-7.

${ }^{21}$ ARChVa, Pl. Civiles, Ceballos Escalera (F), C. 1123-1.
}

Arch. esp. arte, LXXXVI, 344, octUBRE-DICIEMBRE 2013, 275-290, ISSN: 0004-0428 
Este documento supone no solamente conocer la participación de Rodrigo Gil en la conclusión de la Capilla del Obispo, sino también la más que probable intervención de su padre Juan Gil en el origen de la misma, tal y como declara el abovedamiento de dicho espacio ${ }^{22}$.

Así las cosas, el obispo, una vez solucionado el conflicto con la parroquia y convertida la capilla en panteón familiar, pretendió el amueblamiento de la misma con la mayor brevedad. En 1544 se ha documentado la presencia del entallador leonés Cristóbal de Robles para encargarse de los cajones de la sacristía ${ }^{23}$, obra menor que anuncia los grandes encargos que estaban por llegar. Con todo, Margarita Estella ha relacionado las puertas interiores de la capilla y el basamento de grutescos del retablo mayor con éste o con el propio Francisco Hernández, maestros del segundo cuarto del XVI, momento al que asigna el diseño del altar, en extremo ofuscado de arquitectura y talla, tan distinto de las articulaciones de Giralte en Palencia y Valladolid. La existencia de un basamento de planta quebrada, al que se tenía que acomodar la obra, y la combinación de columnas abalaustradas (que el escultor había dejado de emplear en la capilla del doctor Corral de Valladolid ${ }^{24}$ ) con otras de fuste estriado han permitido a esta autora plantear la hipótesis de que Giralte tuvo que adaptarse a un diseño previo ya iniciado ${ }^{25}$.

Con el fin de agilizar las obras el prelado llamó a Giralte ${ }^{26}$, quien durante los primeros cuatro o cinco años se ocupó del retablo mayor y de los sepulcros de los padres del clérigo (fig. 1), que fueron pagados entonces ${ }^{27}$. Después, a partir de 1554, se encargó del enterramiento de don Gutie$\mathrm{rre}^{28}$ y de otras obras menores, concretamente de los dos retablos colaterales, la ornamentación de los órganos, las andas para el Corpus y de un pequeño retablo para el oratorio del comitente. La ejecución de todo ello le ocupó hasta el verano de 1559, cuando, una vez muerto el mecenas, se procedió a la tasación ${ }^{29}$. De todas esas obras se encargaron Giralte, que daba los diseños y modelos

${ }^{22}$ No es este el momento de detenernos en las similitudes con otras obras de Juan Gil, pero las bóveda de la capilla recrean algunas de las soluciones empleadas en la catedral de Segovia, en la Colegiata de Medina del Campo, en Santa María de Coca e incluso en Santa Clara de Briviesca. Por su parte, la imposta que corre bajo las jarjas presenta claras equivalencias con la obra de Juan y Rodrigo Gil de Hontañón. Sobre las bóvedas de crucería de Juan Gil, Gómez MarTínez, 1998.

${ }^{23}$ Estella, 1981: 292.

${ }^{24}$ Parrado del Olmo, 1981: 130-1.

${ }^{25}$ Estella, 1980: 58-60.

${ }^{26}$ Así lo describe el arquitecto Hernán González: ...vido que entendía [Giralte] en las dichas obras del dicho obispo él con su persona e con muchos offiçiales que para ello traía, los quales todos ansymismo entendían en la dicha obra e trabaxavan en ella con mucha diligençia e cuydado. Y este testigo le oyó dezir al dicho Francisco Giralte que las dichas obras las hazía por mandado del dicho obispo, y que le avía traido y persuadido a que se viniesse a esta villa, para que con más brevedad le acabasse las dichas obras, e ansy por ello avía venido. ARChVa, Pl. Civiles, Lapuerta (F), C. 358$1,14^{\mathrm{a}}$ pieza.

${ }^{27}$ El retablo se terminó hacia 1551, pues en julio de dicho año el pintor Juan de Villoldo se comprometió a policromarlo por 490.000 maravedís. CEÁn BERMúdez, 1800, T. V: 263-4. En 1552 se terminó el cenotafio del padre del obispo, tal y como se aclara en una cartela del mismo. Azć́Rate, 1971: 18.

${ }_{28}$ El arquitecto toledano Manuel Álvarez fue en 1554 a Madrid ... a tasar unos rretablos questán en la yglesia de San Gil desta villa, que por mandado de Su Magestad se hizieron, para que este testigo juntamente con el dicho Françisco Giralte tasasen los dichos rretablos, y este testigo quando llegó a esta villa no halló al dicho Francisco Giralte que hera ydo a sacar piedra de alabastro para hazer los bultos del enterramiento del dicho obispo, y este testigo le estuvo aguardando quatro o çinco días, e como no vino hizo la dicha tasaçión con otros, y se fue por entonçes. E antes que se fuesse este testigo fue a la cassa del dicho Francisco Giralte y al taller donde labrava los dichos bultos, e vido questava acabada mucha parte del bulto del dicho obispo e otros bultos que alli le mostraron, e vido que avía hecho mucho de la dicha obra, y estavan entendiendo en ello muchos offiçiales. ARChVa, Pl. Civiles, Lapuerta (F), C. 358-1, 14 aieza.

${ }_{29}$ Así lo aclara el platero Sebastián Álvarez, buen amigo del escultor, que aporta la información más amplia. Según su testimonio primero se ocupó en hazer el rretablo que hizo para el altar mayor de la dicha capilla y dos bultos de los padre y madre del dicho obispo; y una vez concluidos atendió a labrar el enterramiento del prelado y el resto de obras. ARChVa, Pl. Civiles, Lapuerta (F), C. 358-1, $14^{\text {a }}$ pieza. 


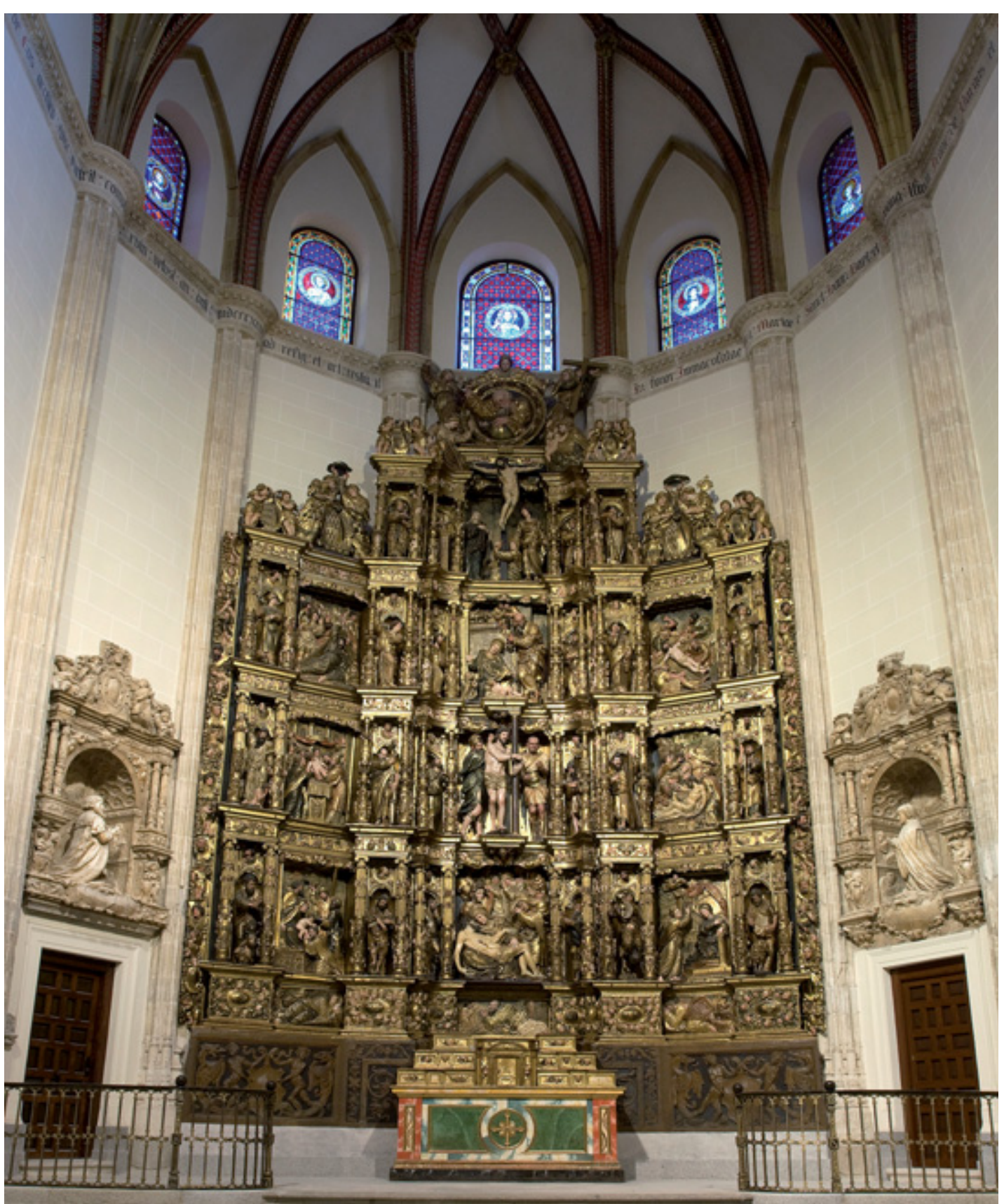

Fig. 1. Francisco Giralte. Retablo mayor y sepulcros del licenciado Francisco de Vargas y doña Inés de Carvajal. Capilla del Obispo. Madrid. Foto E.C.R.A. 
además de tallar directamente la madera, más una gran cantidad de oficiales -hasta dieciocho contabilizó el escultor- que le ayudaron en los trabajos. Así al menos lo recordaba Nicolás de Vergara el Viejo:

...este testigo vido al dicho Francisco Giralte que entendía en las dichas obras trabaxando en ellas personalmente con mucha diligencia y cuydado, y tenía muchos ofiçiales que entendían en labrar en ellas por mandado del dicho Francisco Giralte, y por debuxos y modelos que para lo que hazían en las dichas obras les dava hechos de su propia mano... ${ }^{30}$.

Don Gutierre de Carvajal murió el 27 de abril de 1559. Entonces sólo quedaba por concluir el retablo para su oratorio. Era éste de dos cuerpos, realizado en madera de pino y nogal, del que se había completado parte del ensamblaje con seis columnas redondas sobre sus pedestales, los traspilares y los entablamentos correspondientes de frisos de serafines. Para la tasación los testamentarios acudieron a Valladolid y llamaron a Juan de Juni, elegido por el licenciado Juan de Vargas, hermano del obispo y oidor de la Chancillería; el artista, por su parte, solicitó a Bautista Vázquez el Viejo, el más prestigioso de los berruguetescos. Ambos escultores se juntaron en Madrid en agosto de 1559 y valoraron el enterramiento del obispo, ...cossa por cossa, como es aserrar, y esquadrear, y traçar y labrar toda la arquitatura, y escultura y talla, y tornear colunas, y polir toda la obra, y ansymismo el asiento deste dicho enterramiento con todas sus máquinas de yngenios, que para hazer la dicha obra y asiento semejante se rrequiere..., en 7.910 ducados de oro, con obligación de terminar un dedo de una de las imágenes, añadir el remate de madera del báculo y grabar el epitafio (fig. 2). Los retablos colaterales, sólo de ensamblaje y talla, los estimaron en 136 ducados cada uno; la talla de los órganos grandes, en 34; las andas para el Corpus, en 158, y el retablico del oratorio que estaba sin terminar, en $120^{31}$. En total 8.494 ducados, de los que se habrían de descontar 4.063 que ya había recibido Giralte en vida del obispo.

Los grandes dispendios realizados por el prelado al final de sus días -7.000 ducados gastados en la obtención de la legitimación de su hijo Francisco de Carvajal, la donación de casi todos sus bienes a éste para que pudiera $\operatorname{casar}^{32}$, y la promesa de 28.000 ducados hecha a los jesuitas ${ }^{33}-$ mer- $^{2}$ maron enormemente su liquidez y en consecuencia la de su hermana y heredera, responsable del pago a Giralte. Denunciado este alzamiento de bienes a la justicia, un juez de comisión entró en las propiedades del hijo del prelado y ejecutó unas tierras que habían pertenecido a don Gutierre; las cuales, al no encontrar comprador, se remataron en la heredera para poder atender los compromisos del alma del finado. Con estas heredades, situadas en Velilla y La Rinconada, cerca de Madrid, acudieron los testamentarios a Giralte que las recibió en julio de 1560, dando por zanjada la deuda $^{34}$. Sin embargo, Francisco de Carvajal se opuso a todo ello y denunció el valor de la tasación del sepulcro, que en su opinión no debería haber superado los 4.000 ducados, al tiempo que recurría la transacción de las tierras, obteniendo del juez de comisión la devolución de las mismas. A ello respondió Giralte demandando la entrega de la totalidad de lo tasado, pues los bienes rústicos no alcanzaban a cubrir la deuda ${ }^{35}$.

El pleito se desarrolló entre 1560 y 1564, año en que se produjo el conocido acuerdo entre las partes, merced al cual Giralte recibía de manos de don Francisco las mismas fincas entre-

${ }^{30}$ ARChVa, Pl. Civiles, Lapuerta (F), C. 358-1, $14^{\text {a }}$ pieza.

31 ARChVa, Pl. Civiles, Lapuerta (F), C. $359-1,18^{\mathrm{a}}$ pieza, ff. 688 y ss.

${ }^{32}$ Marqués de Saltillo, 1935: 244-252. Francisco de Carvajal casó con María de Mendoza y Pacheco sobrina de Gonzalo Chacón, señor de Casarrubios del Monte. ARChVa, LA PUERTA (F), C. 357-1, $3^{\mathrm{a}}$ y $5^{\mathrm{a}}$ piezas.

${ }^{33}$ Rodríguez Gutiérrez de Ceballos, 1967: 87.

${ }^{34}$ ARChVa, Pl. Civiles, Lapuerta (F), C. 356-1, $1^{\text {a }}$ pieza.

35 ARChVa, Pl. Civiles, Lapuerta (F), C. 359-1, $1^{\text {a }}$ pieza, ff. 585 y ss. 


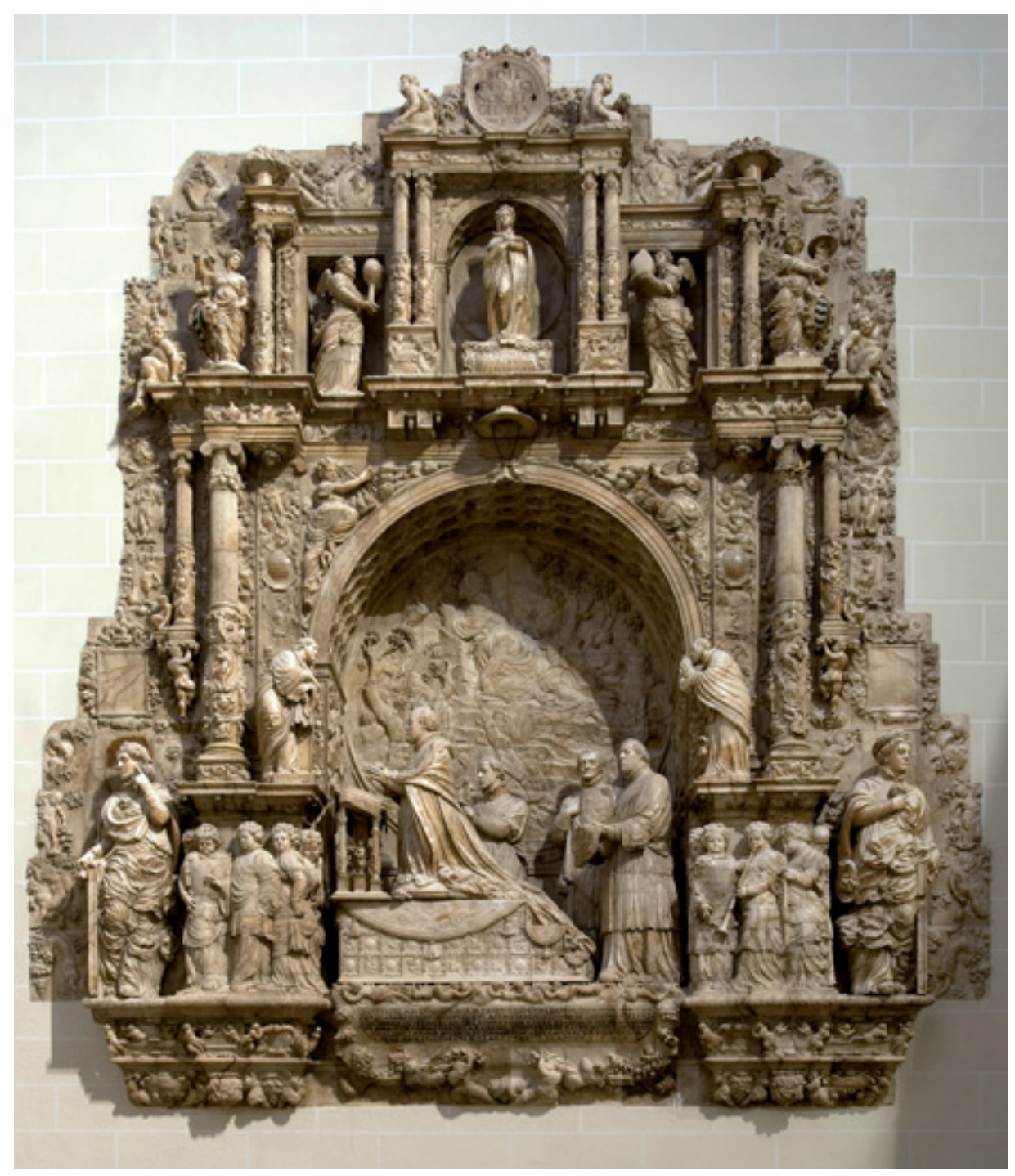

Fig. 2. Francisco Giralte. Sepulcro del obispo Gutierre de Carvajal. Capilla del Obispo. Madrid. Foto E.C.R.A.

gadas inicialmente por doña Leonor de $\operatorname{Vargas}^{36}$ y alcanzaba carta ejecutoria del tribunal vallisoletano ${ }^{37}$.

En 1562 se hicieron unas probanzas testificales, a las que fueron llamados los principales artistas de Madrid y su entorno. Para entonces la situación artística en el Reino y fundamentalmente en Madrid estaba en plena ebullición. La muerte de Alonso Berruguete en 1561 coincidió con el

${ }^{36}$ García Chico: 1941: 15-6. Posteriormente procedería a venderlas. Martín Ortega, 1961: 124.

${ }^{37}$ ARChVa, Registro de Ejecutorias, C. 1057-34. 
traslado de la Corte a la villa. Con ella llegaron escultores como Pompeyo Leoni y Jácome Trezo, arquitectos como Juan Bautista de Toledo y, al año siguiente, pintores como Gaspar Becerra. Giralte intentará no desvincularse de la nueva corriente y entablará amistad con los recién llegados, lo que queda reflejado con nitidez en los testimonios aportados al pleito. La influencia de Giralte en el ambiente artístico madrileño impidió a Francisco de Carvajal encontrar artistas que se prestaran a testificar contra el palentino ${ }^{38}$, por lo que tuvo que conformarse con articular las consabidas tachas contra los presentados por el escultor ${ }^{39}$.

Giralte llamó a dos grupos de testigos en mayo y junio de $1562^{40}$. Por un lado a familiares del obispo y clérigos relacionados con la capilla como Rodrigo de Vargas, primo del finado, y uno de sus albaceas; Pedro de Lorenzana, capellán mayor; Francisco Barragán, capellán; Gaspar de Bedoya, cura de Santa María de la Almudena y secretario que había sido del obispo, y Martín Solano, sacristán mayor. Por otro, a artistas de Madrid, Toledo y Alcalá de Henares, entre los que sobresalen los arquitectos Manuel Álvarez y Hernán González, ambos vecinos de Toledo, y el cortesano Juan Bautista de Toledo; los escultores Nicolás de Vergara el Viejo y Diego de Velasco, toledanos, Miguel Urrea y Felipe Ortiz, alcalaínos, y los cortesanos Pompeyo Leoni y Jácome Trezo. También convocó a su amigo el platero madrileño Sebastián Álvarez ${ }^{41}$. A todos ellos les preguntó por la calidad del sepulcro, que él consideraba una de las más ynsines y esçelentes obras de enterramiento en el arte dél que ay en estos rreynos y fuera dellos; acerca de los numerosos gastos que le había ocasionado el alto número de oficiales que tuvo que contratar; y sobre si podía valorarse en más dinero del que calcularon los tasadores. También los interrogó por el grado de satisfacción del comitente y sobre la estimación que él mismo disfrutaba: que Francisco Giralte, al tiempo que començó la dicha obra, y antes e después, a sydo y es un onbre insine y famosso en su arte...

Por supuesto, a todas estas cuestiones contestaron los testigos de forma favorable, pero se constatan silencios muy significativos que parecen eludir algunas cuestiones delicadas. A la pregunta sobre el prestigio de Giralte, todos se limitaron a suscribirlo sin enumerar ninguna de las obras en que sustentar dicha aseveración -a excepción de las de la propia capilla-, indicativo de su escasa presencia en la escultura madrileña, centrado como había estado en los encargos de don Gutierre. A pesar de ello, algunos de los llamados informaron de tasaciones efectuadas con el palentino, como la cancelada para San Gil, ya citada ${ }^{42}$, o las realizadas, también en compañía de Manuel Álvarez, en la catedral de Toledo y Maqueda ${ }^{43}$. También se describieron las frecuentes visitas que los artistas madrileños y toledanos realizaban a la capilla o al taller de Giralte, pues, como dice Nicolás de Vergara el Viejo, ... cada vez que venya [a Madrid] procurava de yr a ver las dichas obras por ser cossa tan ynsine... Allí conocieron

${ }^{38}$ Así solicitaba el procurador de don Francisco una prórroga al tribunal por no poder ...hallar testigos tan fáçilmente, mayormente que mi parte los a de buscar excultores y hombres que entiendan del ofiçio que usa la parte contraria. ARChVa, Pl. Civiles, Lapuerta (F), C. 356-1, $1^{\text {a }}$ pieza, f. 399.

${ }^{39}$ Por ejemplo, Yten, Ponpeyo León, escultor, y Juan Bautista de Toledo, alquitete, e Jácome de Trezo, escultor, estos ansimismo antes e al tienpo que dixesen sus dichos en esta causa heran grandes amigos, allegados e paniaguados del dicho Francisco Giralte, y no tenían los ofiçios de escultores como dizen, y heran personas pobres de muy poco crédito. ARChVa, Pl. Civiles, Lapuerta (F), C. 359-1, $1^{\text {a }}$ pieza.

${ }^{40}$ Las declaraciones, en ARChVa, Pl. Civiles, Lapuerta (F), C. 358-1, 14 a pieza.

${ }^{41}$ Estas son las edades y las profesiones que declaran en junio de 1562: Manuel Álvarez, arquitecto, vecino de Toledo, más de 40 años; Pompeyo Leoni, escultor de Su Majestad, 28; Hernán González, arquitecto, vecino de Toledo, 48; Miguel de Urrea, entallador y arquitecto, vecino de Alcalá de Henares, 45; Felipe Ortiz, escultor, también de Alcalá, más de 46; Diego de Velasco, escultor, vecino de Toledo y estante en Madrid, 50; Nicolás de Vergara, también escultor y estante en Madrid, vecino de Toledo, 40; Juan Bautista de Toledo, regio arquitecto y estante en Corte, 44; Jácome Trezo, escultor de Su Majestad, estante en Corte, 48; Sebastián Álvarez, platero, vecino de Madrid, 37.

42 Véase la nota 28. Se trata de los retablos mayor y colaterales realizados desde 1552 por el pintor Diego de Urbina y el imaginario Juan de la Plaza y costeados por el Emperador. Cruz Valdovinos, 1995: 41

${ }^{43}$ El retablo mayor de Santa María de Maqueda se terminó en agosto de 1554. López de Ayala, 1958: 160. 
a los oficiales que lo asistían, que lamentablemente no personalizan, los cuales, en ocasiones, pasaron más tarde a trabajar para algunos de los testigos, caso del alcalaíno Felipe Ortiz.

Más interés tienen las valoraciones sobre el sepulcro. Igual que en el caso anterior todos se muestran favorables y consideran el monumento del obispo Carvajal uno de los más excelentes fabricados en España hasta entones, cuando no el mejor. La mayoría de los razonamientos son de trámite, como los de Juan Bautista de Toledo ${ }^{44}$ y los escultores de Alcalá, o basan su juicio en la riqueza del sepulcro, la perfección de la talla y la bondad de su terminación y asiento. Así lo declara, por ejemplo, Jácome Trezo, quien dice que la obra está muy bien acabada y hecha con mucha diligencia y cuydado... lo qual todo está hecho en perfiçión... De igual opinión es Pompeyo Leoni, quien no escatima elogios hacia la obra y la considera una de las mejores de España: Que siendo este testigo persona que entiende del dicho arte, e saver los offiçiales dél e las obras que ay en España, no a visto ni oydo que oviesse otra mejor quella del dicho enterramiento, porque sy otra oviera este testigo lo oviera savido e le ovieran dado notiçia della, como le an dado desta antes queste testigo la viese estando este testigo en Valladolid... Basa su juicio en estar como están tan bien hechas y acabadas y tan en buena perfiçión como lo están, y estar las seys figuras dellas al natural, rredondas, e la demás talla y arquittitura e baxosrrelievos conduçidos a tan buen fin y pulimento y perfiçión como lo está...

Leoni destaca la pretensión naturalista, no sólo en el bulto del finado, sino también en el de sus acompañantes. El carácter retratístico de la representación del homenajeado es inherente en principio al género sepulcral y, aunque el desconocimiento de la apariencia del difunto o la voluntad idealizadora lo impidieran en muchas ocasiones, existen numerosos ejemplos de la búsqueda de una representación veraz e individualizadora del sujeto a lo largo del siglo XVI ${ }^{45}$. El bulto del obispo y de sus acompañantes son verdaderos retratos, así considerados siempre por la familia Vargas-Carvajal; de manera que, cuando a finales del siglo XVI se pretendió completar los sepulcros de la Capilla del Obispo con los de sus sucesores, se tomó como modelo la representación de don Gutierre, retratado del original ${ }^{46}$. Por tanto, deberían poderse identificar los distintos personajes que forman el monumento con facilidad. Desde Ponz se ha intentado poner nombre a las figuras que flanquean al prelado, pero ha sido Ceballos el que ha aportado los de Pedro Lorenzana, capellán mayor de la capilla, situado detrás de su señor con la mitra en la mano, y de Gaspar de Bedoya, secretario del prelado, situado a su $\mathrm{lado}^{47}$. No parece que el tercero sea el provisor de la diócesis placentina, sino más bien Martín Solano, sacristán mayor de la capilla. El conocimiento de la edad de todos ellos, reflejada en los rostros de alabastro, refuerza la identificación: Lorenzana había nacido hacia 1503, tenía por tanto unos 55 años cuando se talló su retrato; Bedoya contaba 27 aproximadamente; Solano, 40, y el obispo, que se supone había nacido en 1506, alcanzó los 53 cuando murió. Todos ellos representan dichas edades y reflejan en sus rostros vulgares e imperfectos la fidelidad al natural (figs. 3 y 4). Leoni se muestra atraído por dicha caracterización que repetirá en alguno de sus monumentos, singularmente en el del cardenal Espinosa, para el que empleó un retrato proporcionado por el sobrino -quien además exigió ver un modelo en barro para comprobar la semejanza ${ }^{48}$-, y en el del arzobispo Valdés ${ }^{49}$.

${ }^{44}$ A la quarta pregunta dixo queste testigo como persona ques del dicho arte e que save hazer e lo entiende le paresçe que la dicha obra del dicho enterramiento es una de las buenas que ay en España según su grado... AChVa, Pl. Civiles. Eusebio Lapuerta (F), C. 358-1, 14 $4^{\mathrm{a}}$ pieza.

${ }^{45}$ Redondo Cantera, 1987, p. 36. Un último ejemplo, muy temprano, en Redondo Cantera, 2011: 687.

${ }^{46}$ Martín Ortega, 1961:125.

47 Ponz, 1793: 117 y Rodríguez G. de Ceballos, 1989: 114.

48 PlON, 1887: 401.

49 García Chico, 1959: 102. Por el contrario, en los cenotafios de El Escorial, donde se buscaba el distanciamiento y la majestuosidad, se idealizaron unos semblantes (AzCÁrATE, 1994: 146-7) que se extrajeron en algunos casos de los retratos iniciados por Leo Leoni muchos años antes (Bustamante, 1997-8: 159 y 1999: 141). Igual ocurrió en el bulto de doña Juana de Austria y en otros de los que Pompeyo desconocía su semblante, como el de Antonio de Sotelo en Zamora,

Arch. esp. arte, LXXXVI, 344, octUBRE-DICIEMBRE 2013, 275-290, ISSN: 0004-0428 


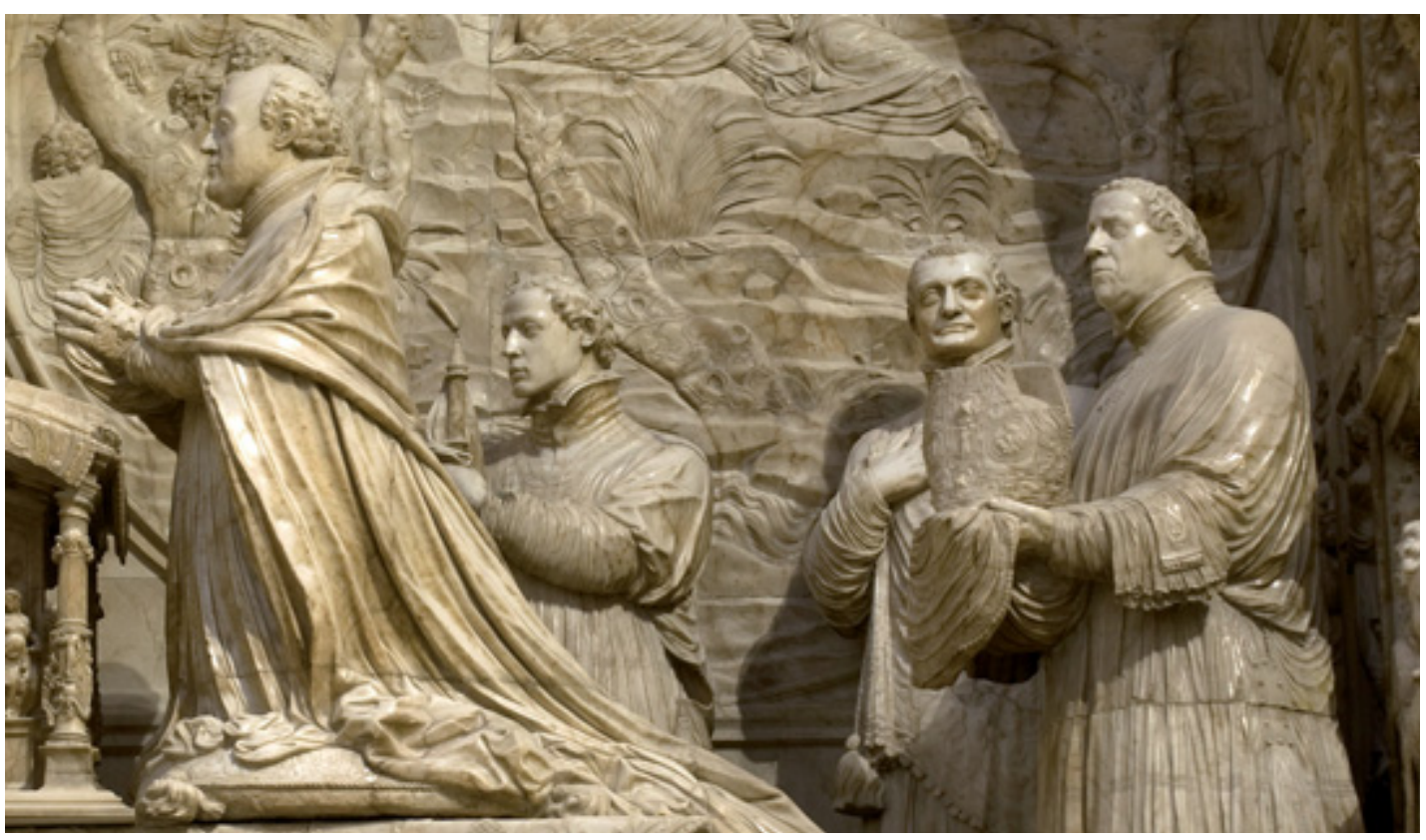

Fig. 3 Francisco Giralte. Sepulcro del obispo Gutierre de Carvajal. Detalle. Capilla del Obispo, Madrid. De izquierda a derecha, don Gutierre de Carvajal, Gaspar de Bedoya, Martín Solano y Pedro Lorenzana. Foto E.C.R.A.

Este último mausoleo presenta muchas similitudes con el de Giralte. La inclusión de los padres en sendos arcosolios a ambos lados del retablo de la colegiata de Salas y la presencia de tres acólitos junto al Inquisidor remiten claramente al ejemplar madrileño ${ }^{50}$. La representación del finado en oración dentro de un sepulcro parietal no era por supuesto una disposición original en la plástica española; tampoco lo era la asociación del mausoleo a un retablo, con el que el difunto en forma de escultura pétrea quedaba vinculado en oración perpetua. Uno de los ejemplos más grandiosos, donde se fija ya la separación de los dos esposos a ambos lados de la capilla mayor, es el de los marqueses de Villena en El Parral, monumento donde los difuntos aparecen también en actitud orante $^{51}$. Pero fue entre los maestros del foco burgalés -el más relacionado con el arte del norte de Europa- donde se extendió el uso del arrodillado, en obras de Siloe, Bigarny y Andino ${ }^{52}$.

Precisamente de mano de Siloe y Bigarny nacieron dos de los antecedentes más cercanos para la creación de sepulcro de don Gutierre de Carvajal. Los bultos de los obispos Mercado y Avellaneda se localizan en arcosolios, se disponen genuflexos y se hacen acompañar por dos o tres figuras de santos protectores y asistentes. Estas figuras sobrenaturales se reiteraron en muchos de los sepulcros orantes de los dos primeros tercios del siglo XVI, pero se desvanecen en la época del decoro -en paralelo a la progresiva desaparición del donante en pie de igualdad con las figuras

del que se ha señalado su parecido físico con la imagen de Carlos V de su cenotafio escurialense (González de Zarate y Martín Vaquero, 1987: 112).

${ }^{50}$ Redondo Cantera, 1987: 36. Estella, 1994: 39.

${ }^{51}$ Parrado del Olmo, 1981b:104 y ss.

52 Redondo Cantera, 1987: 127. 


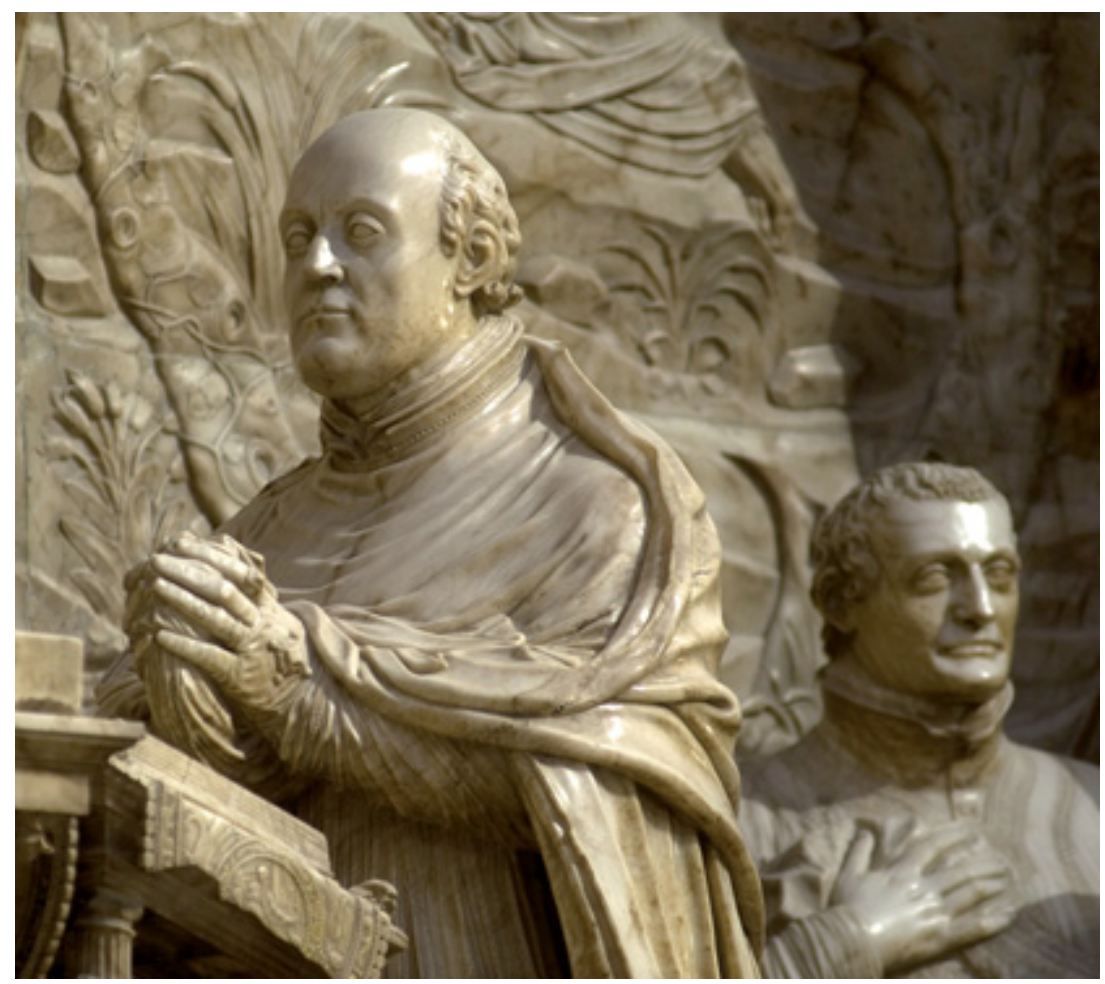

Fig. 4. Francisco Giralte. Sepulcro del obispo Gutierre de Carvajal. Detalle. Capilla del Obispo, Madrid. Foto E.C.R.A.

religiosas en la pintura- debido a su falta de correspondencia espacio-temporal requerida por la Contrarreforma ${ }^{53}$. El que nos ocupa fue uno de los primeros en los que se rompió definitivamente con esa costumbre, pues el prelado se hace acompañar sólo de sus servidores más cercanos que, como hemos visto, son fácilmente identificables.

Sin embargo, la tradición es persistente y el monumento se llena de una compleja iconografía de índole penitencial donde proliferan los personajes religiosos y alegóricos ${ }^{54}$. La existencia de estas figuras en los monumentos funerarios se prolongará durante las décadas siguientes en autores vinculados a Giralte, como su cuñado Manuel Álvarez o el propio Pompeyo Leoni. Aunque no es posible afirmar con total seguridad la participación del primero, experto en la talla de la piedra, en el sepulcro del obispo de Plasencia ${ }^{55}$, la historiografía ha señalado los débitos que sus cenotafios presentan respecto de la obra madrileña. Atribuidos a él los de los I marqueses de Poza y del III conde de Buendía por Azcárate y Parrado respectivamente ${ }^{56}$, ahora nos es posible documentar el segundo de ellos situado en la colegiata de Dueñas. Contratado posiblemente el 12 de septiembre de 1558, ese mismo día el V conde don Fadrique de Acuña entregaba a Álvarez los primeros 30

${ }^{53}$ MARÍAS, 1989: 570.

${ }^{54}$ Rodríguez G. de Ceballos, 1989.

55 Álvarez, después de sus estancias toledanas y vallisoletanas, aparece nuevamente asentado en Palencia desde 1556. PARRADO, 1981a: 278.

56 Azcárate, 1958: 192 y Parrado del Olmo, 1981a: 242 y ss. 
ducados para comenzar a sacar la piedra necesaria ${ }^{57}$. Con un tiempo de labra estimado de ocho meses, lo cierto es que la orden para pagar el último de los plazos la efectuó el conde en febrero de $1560^{58}$. Similar en su concepción al del obispo de Plasencia, se distingue de él por la mayor claridad arquitectónica y sobre todo por la limitación de talla ornamental y figurada que, sin embargo, llena pedestales, netos, tímpanos, enjutas y frontis. Mayor aún es el desarrollo del sepulcro de los I marqueses de Poza en San Pablo de Palencia, donde la semejanza con el madrileño es aún mas evidente. También Pompeyo Leoni gustó del empleo de abundante iconografía religiosa y alegórica. Los mencionados sepulcros del arzobispo Valdés y de Antonio Sotelo son buenos ejemplos. Sólo en aquellos donde actuó en unión de Juan de Herrera se eliminó cualquier figuración complementaria, tal y como ocurre en el cenotafio de doña Juana de Austria en las Descalzas Reales de Madrid ${ }^{59}$ y en los reales de El Escorial.

En el largo proceso constructivo de estos últimos sepulcros no se ha recogido referencia documental alguna al cenotafio del obispo de Plasencia, tan familiar para todos los artistas que participaron en ellos. Sin embargo, y aunque la disposición genuflexa emanó de las disposiciones testamentarias de Carlos V y la ubicación parietal de argumentos italianos estimados por Felipe II $^{60}$, la existencia de tan abundante acompañamiento en el mismo arcosolio encuentra sus orígenes en la tradición española. La presencia, en la plástica hispana del siglo XVI, de la pareja matrimonial en el mismo monumento y la multiplicación de acólitos y figuras sobrenaturales junto al finado o finados, prepararon el camino de una fórmula para la que no sería necesario recurrir a lejanos antecedentes habsbúrgicos. El sentido dinástico buscado en El Escorial con la presencia de la parentela junto a los soberanos estaba implícito en muchas de las capillas funerarias anteriores, donde el linaje o la dinastía quedaban expresados por medio de la representación de los sucesivos descendientes de la casa señorial o real en diferentes sepulcros tallados.

Pero, de vuelta al sepulcro de obispo de Plasencia, distintas motivaciones a las de Pompeyo Leoni tiene la declaración de Nicolás de Vergara el Viejo, más equilibrado y prudente que el resto:

Que este testigo a visto las más obras de enterramientos y sepulcros y más esçelentes y de los mejores maestros que ay en España y fuera della, porque este testigo los a visto por su propios ojos ansy en España como en Françia y en Ytalia e otras partes..., y que este enterramiento... es uno de los ynsines que entre los otros se puede contar y tener por cosa señalada; aunque algunos de los otros an costado muchas más sumas de maravedís que no éste $e^{61}$.

La observación crítica final se repite poco después cuando, tras alabar la bondad e perfiçión de la sepultura, considera justa la valoración de Juni y Bautista Vázquez, maestros honrados que siempre han actuado en conciencia ...en otras tasaçiones de obras para que an sido nombrados de mucha más calidad que no ésta, porque fueron las sillas de la yglesia mayor de la Santa Yglesia de Toledo.

Las palabras de Nicolás de Vergara deben analizarse con atención. Comenzando por el final, éste da a conocer la participación de Bautista Vázquez el Viejo en la tasación de las sillas del coro de Toledo. La de Juan de Juni en unión de Jerónimo Quijano, con la participación como tercero de Pedro Machuca, para tasar los remates de la silla arzobispal con el trascoro en 1547-8 es suficientemente conocida, pero la documentación calla sobre la valoración de los estalos y sus balda-

\footnotetext{
${ }^{57}$ ARChVa, Pl. Civiles, Masas (F), C. 611-1.

${ }^{58}$ ARChVa, Registro de Ejecutorias, C. 1046-6.

${ }^{59}$ García SANZ, 2003: 22.

${ }^{60}$ Bustamante García, 1993: 43-5.

${ }^{61}$ ARChVa, Pl. Civiles, C. 3563-1, 14 ${ }^{\mathrm{a}}$ pieza.
} 
quinos de alabastro. Aunque no hay referencias documentales de esta tasación o tasaciones, ya que fueron dos los maestros implicados, no es creíble que el cabildo se conformase sin una inspección realizada por maestros independientes para comprobar el cumplimiento de las condiciones. Posiblemente tenga que ver con esta intervención el pleito habido con Bigarny y Berruguete a cuenta de unas demasías, quizás apreciadas en estas estimaciones ${ }^{62}$. En una de ellas tuvo que participar Bautista Vázquez, tal y como detalla ahora Vergara.

Aclara también sus viajes a Italia y Francia. El de Italia ya había sido propuesto por Marías a partir de su inventario de bienes y de su familiaridad con el bronce ${ }^{63}$, pero el de Francia era desconocido. Ambos permiten fundamentar el característico estilo del escultor -catalogado por Azcárate como romanista ${ }^{64}$ - en el manierismo internacional y en el clasicismo miguelangelesco. Esta opción estilística estaría detrás de la velada crítica que hace del sepulcro por comparación con la sillería de Toledo. La abundancia de elementos tallados del monumento funerario, donde sólo algunos basamentos, frisos y arquitrabes aparecen desnudos de talla, está muy lejos de la contención ornamental, habitual ya en la segunda mitad del XVI. Contención a la que tanta importancia se había dado en las declaraciones del pleito de La Antigua ${ }^{65}$, que evidentemente Giralte no había interiorizado.

En definitiva, la deposición de Vergara entronca con una inclinación clasicista de la escultura, en formulación durante la década central del siglo pero que se hizo patente con la llegada de Becerra a España. El toledano es consciente del cambio y, a pesar de la voluntad clásica que demuestran algunas imágenes de Giralte, sabe que su arte es el pasado. El de Palencia lo comprenderá cuando su traza para el retablo de las Descalzas Reales sea descartada a favor de la de Becerra. Desde entonces y a pesar de sus buenas relaciones con Pompeyo Leoni y con Juan Bautista de Toledo, quien intentará favorecerle ${ }^{66}$, resultará desplazado hacia el medio rural, quedando el mercado cortesano en manos de los más jóvenes vinculados a las obras reales ${ }^{67}$.

\section{BIBLIOGRAFÍA}

Arias Martínez, Manuel, Alonso Berruguete, Prometeo de la escultura, Diputación de Palencia, Palencia 2011. Azcárate, José María de, Escultura del siglo XVI. Ars Hispaniae, T. XIII, Madrid, 1958.

Azcárate, José María de, La Capilla del Obispo en la iglesia de San Andrés, Ayuntamiento de Madrid, Madrid, 1971.

Azcárate, José María de, "Los grupos funerarios de la basílica", en Campos Fernández de Sevilla, Francisco Javier, La escultura en el Monasterio del Escorial, Real Centro Universitario Escorial-María Cristina, Madrid, 1994, pp. 141-152.

${ }^{62}$ Zarco del Valle, 1916: 254-274.

${ }^{63}$ MARÍAS, 1983: 366. Vergara declara en el pleito que conoce a Giralte desde 1547 aproximadamente. Es decir, Vergara no estaba en Toledo en 1539, año en que acudió el palentino para participar a las órdenes de Berruguete en la sillería catedralicia, ni durante los años siguientes. En 1542, cuando Vergara llegó a la Ciudad Imperial, Giralte ya la había abandonado.

${ }^{64}$ AzCÁrate, 1958, 224.

${ }^{65}$ Martí y Monsó, 1989-1901: 334 y ss.

${ }^{66}$ Rivera, 1984: 262.

${ }^{67}$ Estella, 1999: 202.

Arch. esp. arte, LXXXVI, 344, octUBRE-DICIEMBRE 2013, 275-290, ISSN: 0004-0428 
Bustamante García, Agustín, "Las estatuas de bronce del Escorial. Datos para su historia”, Anuario del Departamento de Historia y Teoría del Arte, V, 1993, pp. 41-58; IX-X, 1997-8, pp. 153-168 y XI, 1999, pp. 129-143.

Casa Martínez, Elena María de la, "El retablo y los sepulcros de la capilla de Nuestra Señora y San Juan de Letrán: análisis historiográfico", Torre de los Lujanes, 2005, pp. 85-128.

Ceán Bermúdez, Juan Agustín, Diccionario Histórico de los más ilustres profesores de las Bellas Artes en España, Madrid, 1800.

Cervera Vera, Luis, "Obras en el alcázar madrileño de Carlos V”, Checa, Fernando (dir.), El Real Alcázar de Madrid, Madrid, 1994, pp. 44-59.

Cruz Valdovinos, José Manuel, "Retablos de los siglos XV y XVI en la Comunidad de Madrid", Retablos de la Comunidad de Madrid, siglos XV a XVIII, Comunidad de Madrid, Madrid, 1995, pp. 29-57.

Estella, Margarita, "Los artistas de las obras realizadas en Santo Domingo el Real y otros monumentos madrileños de la primera mitad del siglo XVI", Anales del Instituto de Estudios Madrileños, XVII, 1980, Madrid, pp. 41-65.

Estella, Margarita, "Las obras artísticas del plateresco madrileño", $A E A$, T. 54, no 215, 1981, pp. 273-296.

Estella, Margarita, "Los Leoni, escultores entre Italia y España”, en Urrea, Jesús, Los Leoni (1509-1608). Escultores del Renacimiento italiano al servicio de la corte de España, Madrid, 1994, pp. 29-62.

Estella, Margarita, "Francisco Giralte entre Berruguete y Juni. Sus contactos con Vázquez en Toledo y con Leoni en Madrid", Archivo Hispalense, 249, 1999, pp. 201-230.

Fernández del Hoyo, Ma Antonia, Juan de Juni, escultor, Universidad de Valladolid, Valladolid, 2012.

Fernández Hoyos, Asunción, El obispo don Gutierre de Vargas, un madrileño del Renacimiento, Caja de Madrid, Madrid, 1994.

García Chico, Esteban, Documentos para el estudio del Arte en Castilla. Escultores, Valladolid, 1941.

García Chico, Esteban, Nuevos documentos para el estudio del Arte en Castilla. Escultores del siglo XVI, Valladolid, 1959.

García Sanz, Ana, "Nuevos datos sobre los artífices de la capilla funeraria de Juana de Austria", Reales Sitios, 155, 2003, pp. 17-25.

Gerard, Veronique, De castillo a palacio. El Alcázar de Madrid en el siglo XVI, Bilbao, 1984.

Gómez Martínez, Javier, El Gótico español de la Edad Moderna. Bóvedas de crucería, Salamanca, 1998.

González de Zárate, Jesús María y Martín Vaquero, Rosa, "En torno al arte sepulcral del siglo XVI. El sepulcro de Antonio de Sotelo y Cisneros en la iglesia de San Andrés de Zamora”, Norba-Arte, 7, 1987, pp. 97-118.

Lampérez y Romea, Vicente, "Las capillas del Obispo y de San Isidro", Boletín de la Sociedad Española de Excursiones, T. VI, 64, 1898, pp. 57-62.

López de Ayala-Álvarez de Toledo, Jerónimo, conde de Cedillo, Catálogo Monumental de la Provincia de Toledo, Diputación de Toledo, Toledo, 1958.

Marías, Fernando, La arquitectura del Renacimiento en Toledo (1541-1631), T. I, Toledo, 1983.

Marías, Fernando, El largo siglo XVI, Taurus, Madrid, 1989.

Marqués del Saltillo, "Los Carvajales madrileños (1559-1795)”, BSEE, 1935, pp. 241-264.

Martí y Monsó, José, Estudios histórico-artísticos relativos principalmente a Valladolid, Valladolid-Madrid, 1989-1901.

Martín Ortega, Alejandro, "Datos sobre Francisco Hernández y Francisco Giralte, en Madrid”, BSAA, XXIII, 1957, pp. 65-76.

Martín Ortega, Alejandro, "Más sobre Francisco Giralte, escultor”, BSAA, XVII, 1961, pp. 123-130.

Parrado del Olmo, Jesús María, Los escultores seguidores de Berruguete en Palencia, Universidad de Valladolid, Valladolid, 1981.

Parrado del Olmo, Jesús María, Los escultores seguidores de Berruguete en Ávila, Caja de Ahorros y Préstamos de Ávila, Ávila, 1981.

Parrado del Olmo, Jesús María, “La obra de Francisco Giralte en Valladolid”, AEA, LXXXII, 326, 2009, pp. 194-226.

Plon, Eugène, Leone Leoni, sculpteur de Charles V, et Pompeo Leoni, sculpteur de Philippe II, París, 1887. Ponz, Antonio, Viage de España, Madrid, 1717 (facsímil en Madrid, 1972).

Redondo Cantera, María José, El sepulcro en España en el siglo XVI. Iconografía y tipología, Centro Nacional de Información y documentación del Patrimonio Histórico, Madrid, 1987. 
Redondo Cantera, María José "La intervención de Felipe Bigarny en el sepulcro de los Reyes Católicos", Pulchrum. Scripta varia en honorem $M^{a}$ Concepción García Gainza, Gobierno de Navarra y Universidad de Navarra, Navarra 2011, pp. 684-689.

Rivera, Javier, Juan Bautista de Toledo y Felipe II (La implantación del Clasicismo en España), Universidad de Valladolid, Valladolid, 1984.

Río de la Hoz, Isabel del, El escultor Felipe Bigarny (h. 1470-1542), Junta de Castilla y León, Salamanca, 2001.

Rodríguez G. de Ceballos, Alfonso, Bartolomé de Bustamante y los orígenes de la arquitectura jesuítica en España, Institutum Historicum Societatis Iesu, Roma, 1967.

Rodríguez G. de Ceballos, Alfonso, "El sepulcro del obispo don Gutierre de Carvajal. Lectura iconográfica", Ephialte, 1, 1989, pp. 107-122.

Urrea, Jesús, Arquitectura y nobleza. Casas y palacios de Valladolid, Ayuntamiento de Valladolid, Valladolid, 1996.

Vasallo Toranzo, Luis, Juan de Anchieta, aprendiz y oficial de escultura en Castilla (1551-1571), Universidad de Valladolid, Salamanca, 2012.

VV. AA, XXXV Coloquios históricos de Extremadura, dedicados a la memoria del obispo D. Gutierre de Vargas Carvajal, C.I.T. Trujillo, Badajoz, 2007.

Zarco del Valle, Manuel R., Datos documentales para la Historia del Arte Español. II, Madrid, 1916.

Fecha de recepción: 12-XI-2012

Fecha de aceptación: 24-I-2013

Arch. esp. arte, LXXXVI, 344, octUBRE-DICIEMBRE 2013, 275-290, ISSN: 0004-0428 